\title{
LA GUERRA CIVIL ESPAÑOLA Y LA CONFERENCIA DE OBISPOS NORTEAMERICANA
}

\author{
POR \\ JOSÉ LUIS GONZÁLEZ GULLÓN \\ Colaborador de Investigación, Universidad de Navarra
}

RESUMEN: La National Catholic Welfare Conference -la organización nacional de católicos de Estados Unidos- lideró la respuesta oficial de los católicos estadounidenses sobre la guerra civil española. Además mantuvo contacto con el episcopado de España a través del cardenal Isidro Gomá. La conferencia de obispos norteamericana condenó al Gobierno de la zona republicana debido a la persecución religiosa y a su dependencia del comunismo. Su posición sobre el general Franco fue más articulada. Deseaba que Franco ganara la guerra pero, a la vez, que España recuperase un sistema democrático.

PALABRAS CLAVE: Guerra Civil, Conferencia de obispos de Estados Unidos, Cardenal Isidro Gomá, Michael J. Ready, Embargo a España

\section{THE SPANISH CIVIL WAR AND THE AMERICAN BISHOPS CONFERENCE}

\begin{abstract}
The National Catholic Welfare Conference issued official statements about the Spanish Civil War. It was in touch with the Spanish Bishops through cardinal Isidro Gomá. The NCWC condemned the Loyalist Government for two main reasons: the religious persecution and the dependence on the communists. Its position about General Franco was more complicated. The NCWC wanted the victory of Franco but at the same time, it desired the recovery of the democratic system in Spain.
\end{abstract}

KEYWORDS: Spanish Civil War, National Catholic Welfare Conference, Cardinal Isidro Gomá - Michael J. Ready, Spanish Embargo

Recibido/Received 2011-07-30

Aceptado/Accepted 2011-10-21

Las vicisitudes de la guerra civil española desbordaron las fronteras ibéricas. Estados Unidos siguió con atención lo que ocurría a pesar de ser un acontecimiento en el que el país no estaba oficialmente involucrado. Los motivos de la contienda, las partes implicadas, la persecución religiosa, las relaciones económicas y diplomáticas, la intervención de ciudadanos norteamericanos en el conflicto y el papel del comunismo fueron temas presentes en la agenda de los políticos y en las 
noticias de prensa. Entre los combatientes que llegaron a España hubo tres mil norteamericanos -la Brigada Abraham Lincoln- que lucharon en la zona republicana. La guerra española importaba. Allí se daban cita diversas concepciones sobre el modo en el que se debían regir las naciones durante las décadas siguientes. ${ }^{1}$

¿Qué postura adoptaron los católicos norteamericanos? ${ }^{2}$ Con veinte millones de bautizados $17 \%$ de la población-, 34.000 sacerdotes, 132 obispos y 5 cardenales, la Iglesia católica era la denominación cristiana más importante en Estados Unidos. ${ }^{3}$ Los católicos comenzaban a desplegar una influencia notable en la sociedad. Muchos formaban parte de la coalición que había otorgado la victoria presidencial a Franklin Roosvelt en 1932 y que contribuyeron a su reelección en el mes de noviembre del año $1936 .^{4} \mathrm{Su}$ fuerte unión en diversos aspectos políticos y sociales, les llevaba a tener frecuentes roces con las denominaciones protestantes.

Desde el comienzo, la prensa católica -más de trescientas publicaciones periódicas- dedicó amplio espacio a la guerra civil. ${ }^{5}$ A diferencia de la mayoría de publicaciones norteamericanas, religiosas o civiles, los católicos se alinearon a favor de la zona nacional. La revista semanal America, editada por los jesuitas, fue el prototipo de ese apoyo. ${ }^{6}$ The Commonweal, dirigida por fieles laicos, osciló entre el apoyo a Franco y la neutralidad. ${ }^{7}$ Sólo The Catholic Worker, de ideario pacifista, se opuso a la guerra. Los periódicos semanales de las diócesis recogieron las noticias que llegaban desde el departamento de prensa de la conferencia de obispos (NCWC News Service), siempre favorables al bando nacional.

La mayoría de los obispos norteamericanos se interesó por lo que sucedía en España, especialmente cuando llegaron noticias alarmantes acerca de la persecución religiosa. Algunos obispos

\footnotetext{
${ }^{1}$ Bosch, A. 2012. Miedo a la democracia: Estados Unidos ante la Segunda República y la Guerra Civil española. Barcelona: Crítica.

${ }^{2}$ Para conocer la situación del catolicismo en Estados Unidos Unidos en los años treinta, cf. Carey P. W. 2004. Catholics in America. A History. Westport (CT): Praeger; Dolan, J. P. 1985. The American Catholic Experience: a History from Colonial Times to the Present. Garden City (NY): Doubleday \& Co. El mejor estudio en castellano sobre la guerra civil española y los católicos norteamericanos es el de Tusell, J. y García Queipo de Llano, G. 1993. El catolicismo mundial y la guerra de España: 297-364. Madrid: BAC. Cf. también dos tesis inéditas: Arrambide, P. M. 1976. The reaction of the Protestant and Catholic churches in the U.S.A. to the Spanish Civil War. Memphis State University; y Frank, R. L. 1978. The rhetoric of American Catholicism on the Spanish Civil War. University of Pittsburgh.

${ }^{3}$ La Iglesia católica había erigido 106 diócesis, con sus respectivos obispos residenciales, además de tener otros cinco obispos con jurisdicciones particulares (cf. Maynard, T. 1948. The Story of American Catholicism: 617-648. New York: The Macmillan Company). Aunque Estados Unidos y la Santa Sede no tenían relaciones diplomáticas, el Vaticano mantenía una Delegación Apostólica en Norteamérica. Cf. 1936. Annuario Pontificio: 731. Cittá del Vaticano.

${ }^{4}$ Cf. Flynn G. Q. 1976. Roosevelt and Romanism. Catholics and American Diplomacy, 1937-1945: 35 ss. Westport (Conn.): Greenwood Press.

${ }^{5}$ La postura de la prensa católica ha sido analizada con cierto detalle en Sánchez, J. M. 1987. The Spanish civil war as a religious tragedy: 184-198. Notre Dame (Indiana): University of Notre Dame Press; y Prudlo D. 2006. "American Catholics and the Spanish Civil War". Faith and Reason 31,2: 243-273.

${ }^{6}$ El director de America, el jesuita Francis X. Talbot, fue una de las personas mejor informadas en Estados Unidos acerca de la guerra civil española. Sus opiniones sobre la guerra pueden seguirse en los America Magazine Archives, Special Collections Research Center, Georgetown University, Washington, D.C.

${ }^{7}$ Cf. Van Allen, R. 1974. The Commonweal and American Catholicism: the magazine, the movement, the meaning: 60-70. Philadelphia: Fortress Press.
}

Hispania Sacra, LXIV Extra I, enero-junio 2012, 315-341, e-ISSN: 1988-4265, doi: 10.3989/hs.2012.033 
tuvieron su propia agenda con respecto a la guerra civil, especialmente en el envío de dinero o de otro tipo de ayudas. Pero la toma de posturas oficiales sobre el conflicto español recayó en la National Catholic Welfare Conference (NCWC), la organización nacional de los católicos norteamericanos. Ella se encargó de mantener el contacto institucional entre los obispos norteamericanos y los españoles en los temas de interés general para la Iglesia de Estados Unidos. Además, informó sobre lo que sucedía en España a la jerarquía estadounidense.

La guerra civil fue un problema complejo para la NCWC. Por una parte, los obispos norteamericanos rechazaban la Segunda República. Antes de la guerra había asuntos preocupantes, como el anticlericalismo intelectual manifestado en la prohibición de enseñanza a los religiosos, la supresión de los jesuitas, las dudas sobre la transparencia electoral que dio la victoria del Frente Popular y el anticlericalismo violento desatado entre febrero y julio de 1936. Después, el comienzo de la guerra el que hizo culpable al Gobierno a los ojos de la jerarquía norteamericana: las matanzas sistemáticas de clérigos ni fueron cortadas ni fueron condenadas por la autoridad republicana, y el culto católico fue prohibido o abolido por vía de hecho.

Pero, por otra parte, la solución de una dictadura militar para España no gustaba a la NCWC. Los obispos norteamericanos creían en la democracia y en la tradición liberal que defendía la libertad religiosa. Explicar a la opinión pública norteamericana que se deseaba la victoria de Franco y que, en cambio, se rechazaba su régimen dictatorial no era tarea sencilla. La prensa liberal, las comunidades protestantes e incluso algunos sectores católicos iban a mostrar su asombro o su rechazo ante la actitud de la NCWC.

Este artículo analiza la posición y la actuación de la NCWC durante la guerra civil. Desea conocer cómo comprendió la guerra civil y qué contactos y estrategias comunicativas adoptó.

\section{LA NATIONAL CATHOLIC WELFARE CONFERENCE}

En julio de 1936, la NCWC estaba más pujante que nunca. Creada durante la primera Guerra Mundial, la organización de católicos norteamericanos coordinaba la relación entre la jerarquía católica, a la vez que ofrecía a los obispos un instrumento de información y de contacto. ${ }^{8}$ Atendía, además, a las diversas organizaciones religiosas y seculares de carácter supradiocesano, presentes a lo largo y ancho del país. Tenía su sede en la capital, Washington, con el fin de mantener las oportunas relaciones con el Congreso, la Casa Blanca y las embajadas, de modo muy particular con la Delegación Apostólica de la Santa Sede. Estaba dividida en cinco departamentos: ejecutivo, jurídico, educativo, de acción social y de prensa.

El presidente de la NCWC era el obispo de Detroit, Edward A. Mooney. Por ser un obispo residencial, acudía a Washington pocas veces al año. El gobierno diario de la NCWC recaía sobre la

${ }^{8}$ El National Catholic War Council se creó en 1919 para colaborar en la atención social de los combatientes. Después de la guerra dio paso a la NCWC, una agencia que coordinaba los intereses y actividades de los católicos norteamericanos. Su lema "For God and Country" resumía los dos aspectos que la configuraban: ser a la vez buenos fieles católicos y ciudadanos norteamericanos. En 1966, la NCWC fue sustituida por la actual United States Conference of Catholic Bishops, con las competencias propias de las conferencias episcopales previstas en el Concilio Vaticano II. 
secretaría general, el Administrative Board of Archbishops and Bishops. El secretario general era mons. Michael J. Ready. ${ }^{9}$

Desde el comienzo de la guerra civil, Ready se interesó por lo que sucedía en España. No leía ni hablaba español, por lo que se valió de los informes y traducciones que le pasaron sus colaboradores. Mons. Ready dio el valor y el cauce que creyó oportuno a la información que recibió: muchas veces, archivó los informes después de haberlos estudiado; otras veces, los comentó con sus colaboradores o los envió a los demás obispos americanos. También escribió a España solicitando noticias. Su interlocutor habitual fue el cardenal Isidro Gomá. ${ }^{10}$ Esta correspondencia tuvo lugar por correo postal, aunque alguna vez hubo intercambio de telegramas, sobre todo cuando Ready necesitaba recibir una información urgente. ${ }^{11}$

El hombre clave para los asuntos de España y del mundo latinoamericano fue William F. Montavon, director del departamento jurídico de la NCWC. ${ }^{12}$ Había sido el corresponsal de la prensa católica norteamericana en España en septiembre y octubre de 1931. Desde su despacho en la NCWC, envió a Ready informes sobre la situación de la guerra civil una o dos veces al mes. Esos informes resumían las noticias publicabas por la prensa española -sobre todo, la prensa afín a Franco-, y también las noticias que provenían de otras fuentes, como el Excelsior de México.

Colaboró también con Ready para los asuntos españoles Frank A. Hall, director del NCWC News Service. Hall redactó y envió noticias de prensa a Ready o a Montavon para que pudieran analizar la situación española. Además de la prensa, Hall recibió noticias desde la zona nacional gracias a Manuel Graña, antiguo redactor de El Debate y sacerdote, que escribía en inglés porque había estudiado periodismo en la Universidad de Columbia. Hall también envió servicios de noticias a agencias, revistas y periódicos católicos del país.

\section{LA PERSECUCIÓN RELIGIOSA Y LA PROPAGANDA}

En 1936, España contaba con 33.000 presbíteros diocesanos y 6.800 religiosos. 6.549 clérigos, el $16,4 \%$, fueron asesinados durante la guerra civil. Si contemplamos únicamente la zona republicana, ese porcentaje de clero asesinado asciende a algo más del 30\%. Esta estadística es acorde con el carácter de

${ }^{9}$ Michael Joseph Ready nació el 9 de abril de 1893. Era hijo de inmigrantes irlandeses. En 1918, Ready fue ordenado sacerdote de la diócesis de Cleveland. Fue nombrado adjunto del secretario general de la NCWC en 1931, y cinco años más tarde pasó a ser el secretario general. Ready recibió la ordenación episcopal en 1944 y ocupó la sede de Columbus, Ohio. Falleció el 2 de mayo de 1957.

${ }^{10}$ Isidro Gomá y Tomás nació en La Riba (Tarragona) el 19 de agosto de 1869. Recibió la ordenación sacerdotal en junio de 1895, y la episcopal en 1927. Ocupó la sede de Tarazona hasta julio de 1933, momento en que fue nombrado arzobispo de Toledo. En diciembre de 1935 el papa Pío XI lo creó cardenal. Lideró la Iglesia española durante la guerra civil. Falleció el 22 de agosto de 1940. Cf. Dionisio Vivas, M. A. 2011. Isidro Gomá ante la dictadura y la República: pensamiento político-religioso y acción pastoral. Toledo: Instituto Teológico San Ildefonso.

${ }^{11}$ Lógicamente, hubo cartas entre obispos de una y otra nación que no pasaron por la NCWC. Ahora bien, la conferencia de obispos fue la encargada de coordinar las declaraciones colectivas de la jerarquía norteamericana en relación con la guerra española.

${ }^{12}$ William F. Montavon nació en South County, Ohio, el 14 de julio de 1874. Estudió derecho en la Univeridad de Notre Dame. Durante diez años, trabajó para diversas compañías en Latinoamérica. Dese 1926 y hasta su jubilación fue director del Legal Department de la NCWC. Falleció en 1959.

Hispania Sacra, LXIV Extra I, enero-junio 2012, 315-341, e-ISSN: 1988-4265, doi: 10.3989/hs.2012.033 
revolución extrema que se vivió al comienzo de la guerra. El clero fue perseguido con el fin de ser eliminado físicamente.

A principios de agosto de 1936, llegaron a Estados Unidos las primeras noticias contrastadas sobre asesinatos de clero. El día 24, el NCWC News Service envió a la prensa católica una traducción de la Instrucción pastoral de los Obispos de Vitoria y Pamplona, fechada el 6 de agosto. ${ }^{13}$

El 1 de septiembre, John T. McNicholas, arzobispo de Cincinnati, escribió una pastoral acerca de la guerra española. Era el primer líder eclesiástico americano que trataba por extenso sobre el conflicto. Su carta recogía las noticias, todavía inciertas en cuanto al número pero indudables, que referían el asesinato de sacerdotes y monjas. El obispo solicitó las oraciones de sus fieles, decretando un triduo de reparación, con la exposición del Santísimo Sacramento. Además, mencionó lo que juzgaba el fondo del conflicto español: el comunismo. ${ }^{14}$ Los asesinatos en masa de clero eran una muestra de que en España se deseaba llevar a cabo las mismas acciones que en Rusia o en México: destruir la religión y el sistema de derechos humanos que el cristianismo protegía. ${ }^{15}$

En noviembre, tuvo lugar la reunión anual de los obispos norteamericanos. Fijaron su postura oficial: condenar los asesinatos del clero, y no mencionar a ninguna de las dos partes en conflicto. ${ }^{16} \mathrm{Se}$ volvía a declarar al comunismo culpable. Este sistema ateo se caracterizaba por la violencia. No negaba solamente la existencia de Dios, sino que la combatía con virulencia, destruyendo los templos y asesinando a los ministros del culto. ${ }^{17}$

\section{LA PROPAGANDA SOBRE LA GUERRA CIVIL}

Cuatro meses después del comienzo de la guerra civil, la opinión pública supo que Madrid no caería fácilmente en manos de las tropas franquistas y que, por tanto, el desenlace de la guerra se postergaba. Y, con el alargamiento del conflicto, se incrementó la propaganda.

En Estados Unidos, la propaganda estuvo presente en las publicaciones y en las intervenciones públicas. Los argumentos se simplificaron hasta hacerse falsos en ocasiones. Si algunos hablaban de la guerra como una lucha entre la democracia y el fascismo, otros se referían al conflicto como un duelo entre el comunismo y el cristianismo.

${ }^{13}$ La Instrucción pastoral había sido redactada por el cardenal Isidro Gomá, que residía por entonces en Navarra. La carta prohibía a los católicos pelear en el bando republicano pues, según decía, estaba dominado por el comunismo. Cf. 1936. Boletín Oficial Eclesiástico del Obispado de Pamplona 1832: 317-322.

${ }^{14}$ La jerarquía católica, comenzando por la Santa Sede, pensó durante la guerra civil que el verdadero problema de España era el comunismo. Su fuerza - que ya era grande en el momento del estallido del conflicto armado- fue en aumento durante la guerra. Cf. el informe que el nuncio Federico Tedeschini envió al Vaticano el 20 de mayo de 1936 en Hernández Figueiredo, J. R. 2010. "Avances y estado del comunismo en vísperas de la guerra civil española, según los informes inéditos del Archivo Secreto Vaticano”. Analecta Sacra Tarraconensia 83: 817-906.

${ }^{15}$ La carta puede verse en el Archivo de la Catholic University of America (en adelante ACUA), National Catholic Welfare Conference, Box 50 Folder 21 (International Affairs: Spain, 1932-1936).

${ }^{16}$ Cf. Tusell, J. y García Queipo de Llano, G. 1993: 313.

${ }^{17}$ Cf. 1936. "Archbishop Rummel's Sermon at Opening of NCWC Convention". Catholic Action: 13. 
Un caso de propaganda fue la invitación hecha a algunos sacerdotes españoles que creían en la causa republicana para que hablaran en Estados Unidos. ${ }^{18}$ Como eran "católicos oficiales", consagrados que vestían con los atuendos clericales, su sola presencia mostraba que el catolicismo no era exclusivo de la zona nacional. Ya en el mes de octubre de 1936, tres personas llegaron a Estados Unidos para hablar a favor de la República: Marcelino Domingo, antiguo ministro de Instrucción Pública; Isabel de Palencia, socialista; y el franciscano Luis Sarasola. El viaje estuvo esponsorizado por la American League against War and Fascism, organización comunista. La prensa destacó la presencia del religioso en la comitiva, aunque se supo que estaba en Estados Unidos sin el permiso de sus superiores. ${ }^{19}$

También en octubre, Earl Browder, candidato comunista para la presidencia de Estados Unidos, afirmó por radio que su partido entendía la lucha en España como un conflicto entre dos sistemas, «democracy or fascism». ${ }^{20}$ Según Browder, el fascismo español se encubría apelando a una «cruzada por Dios, una cruzada, fíjense, en la que las tropas de Mahoma asesinan a inocentes hombres y mujeres cristianos». ${ }^{21}$

Esa propaganda fue denunciada por la NCWC. En los primeros meses de la guerra civil, William F. Montavon fue el representante de la conferencia de obispos ante el público y los medios de comunicación. El 10 de noviembre, en un encuentro que tuvo lugar en Baltimore, Montavon salió al paso de las declaraciones de Browder. Afirmó que la tradición española era ajena a los sistemas totalitarios. El problema religioso había aparecido primero en la República y después, en la guerra, porque los Gobiernos republicanos lo habían utilizado como bandera política. ${ }^{22}$ A finales de ese mes, la NCWC tradujo la carta del cardenal Gomá El Caso de España, y la envió a todos los obispos norteamericanos. Y en el mes de diciembre, Montavon publicó un folleto titulado Insurrection in Spain, en el que analizaba las causas que habían producido el colapso de la República en los meses anteriores a la guerra. ${ }^{23}$

En la mente de la NCWC quedó fija la idea de que la guerra española era una lucha que se alimentaba en buena medida con la propaganda pro-republicana. En enero de 1937, mons. Ready pasó una carta a su adjunto en la secretaría general, Howard J. Carroll, para explicarle cómo entendía la actitud de la prensa:

${ }^{18}$ Sobre las visitas de estos católicos, cf. Sánchez J. M. 1992. "Priests and Suspect Catholics: Visitors from Loyalist Spain to America". The Catholic Historical Review LXXVIII/2: 207-216.

${ }^{19}$ Unos meses más tarde, hubo otra visita de un clérigo. En mayo y junio de 1937, el sacerdote Michael O'Flanagan, suspendido a divinis, hizo una gira por Estados Unidos para hablar sobre la guerra civil. Estaba invitado por los American Friends of Spanish Democracy, asociación de protestantes norteamericanos favorable al Gobierno de la República. Cf. 1937. “Comment”. America 57: 98. El presidente de los American Friends era Francis J. McConell, Obispo de la Iglesia Episcopal Medodista en New York.

${ }^{20}$ La transcripción del mensaje de radio de Earl Browder, "What Spain Means to America", se encuentra en ACUA, National Catholic Welfare Conference, Box 50 Folder 21 (International Affairs: Spain, 1932-1936).

${ }^{21}$ «They try to cover up the fascist invasion as a crusade for God, a crusade, mind you, by Mohammedan mercenaries who murder innocent Christian men and women» (ídem).

${ }^{22}$ Cf. William F. Montavon, "Civil War in Spain", 10-XI-1936, p. 28, en ACUA, National Catholic Welfare Conference, Box 50 Folder 21.

${ }^{23}$ Cf. Montavon W. F., 1936. Insurrection in Spain. Washington (D.C.): National Catholic Welfare Conference. 
«Es una desgracia ver que las propagandistas de noticias de los rojos españoles han conseguido presentarse a sí mismos como defensores de la democracia. Al menos una gran parte de la prensa americana les otorga esta reputación» ${ }^{24}$.

La labor de contrarrestar la propaganda republicana no recayó directamente sobre la conferencia de obispos, salvo en contadas ocasiones. La llevaron a cabo los periódicos y revistas católicos. En muchos casos, polemizaron sobre los sucesos que aparecían en la prensa americana liberal porque no se correspondían con las informaciones que ellos habían recibido. ${ }^{25}$ Por ejemplo, criticaron que diesen noticias, sin contrastar, que referían un bombardeo indiscriminado de Guernica; que los niños vascos hubiesen salido del país debido a la presión de las tropas nacionales; que fuese escandaloso ver tropas de musulmanes en las filas de los católicos nacionales; o que hubiese división dentro del clero español. ${ }^{26}$

El 19 de marzo de 1937, Pío XI publicó la encíclica Divini Redemptoris sobre el comunismo ateo, con la condena explícita de esta doctrina. La encíclica daba la razón a quienes veían el comunismo internacional agazapado detrás de la República española en guerra, especialmente por la violencia desatada contra los ministros católicos. El 16 de abril de 1937, William F. Montavon habló por la radio de la National Broadcasting Company, en Washington. Denunció la persecución comunista en la zona republicana, aunque no apoyase incondicionalmente a la otra zona: recordó que el Papa había hablado ya dos veces sobre la situación española y que, en ambos casos, había denunciado la persecución por motivos religiosos, había expresado su cercanía hacia las personas que sufrían en España, y no había hablado «with full approval of armed insurrection». ${ }^{27}$

\section{EL ENVÍO DE AYUDA ECONÓMICA}

A partir de noviembre de 1936, diversas organizaciones estadounidenses enviaron a España ayuda económica. Los subsidios del lado republicano fueron más cuantiosos. Destacaron dos organizaciones, ambas con cooperación formal del Partido comunista de Estados Unidos: la American League Against War and Fascism y el North American Commitee to Aid Spanish Democracy. ${ }^{28}$ Ésta asistió económicamente a la Brigada Lincoln, e invirtió parte del dinero recaudado en la organización de actos de propaganda en Estados Unidos. ${ }^{29}$ En 1938, las asociaciones que ayudaban a la causa

24 «It is unfortunate that the news propagandists of the Spanish Reds have been successful in representing themselves as the defenders of democracy. At least one American press for the most part gives them that reputation» (carta de Michael J. Ready a Howard J. Carroll, 4-I-1937, en ACUA, Collection 10, Box 135, Folder 4).

${ }^{25}$ Cf. Toomey, J. A., 1937. "Pointing a finger at press propaganda. Great power lies latent in the pews of our churches". America 58: 106.

${ }^{26}$ Cf., por ejemplo, 26-VI-1937. "Catholic Press is Attacked for Demanding Truth". The Brooklyn Tablet; y Ferger E. J. 1937. “Moors and Clergy Loyal to Nationalists”. America 57: 392.

27 Transcripción del discurso en ACUA, National Catholic Welfare Conference, Box 50 Folder 22.

${ }^{28}$ La documentación sobre estas organizaciones puede verse en Spanish Refugee Relief Association Records, Rare Book and Manuscript Library, Columbia University Library. Cf. también Communism in the United States. A survey by the NCWC Department of Social Action, Washington D.C., National Catholic Welfare Conference 1937, pp. 12-13.

${ }^{29}$ Cf. Nota de prensa de N.C.W.C. News Service, 29-VIII-1938, en ACUA, National Catholic Welfare Conference, Box 51 Folder 2. 
republicana se fundieron en el North American Committee and Medical Bureau to Aid Spanish Democracy. ${ }^{30}$

Por su parte, casi todo el dinero norteamericano que llegó a los nacionales salió de los católicos. El obispo de Brooklyn, John Molloy, fue el primero en hacer una campaña en The Brooklyn Tablet. En febrero de 1937 recolectó 24.000 dólares. En los meses siguientes surgieron dos organizaciones católicas. Una fue el American Commitee for Spanish Relief, organización nacional y no confesional. Este Comité se inscribió oficialmente en el mes de abril. Fue dirigido Patrick F. Scanlan, editor de The Brooklyn Tablet, y su secretario general fue Michael Williams, editor de The Commonweal. ${ }^{31}$ El dinero se destinó exclusivamente a ayuda médica y medicinas, comida, vestido y asilo.

En un principio, pensaron que su contacto en España fuese el cardenal de Toledo, Isidro Gomá, quien se encargaría de encauzar los fondos. Concretamente, se establecía que el dinero fuese destinado a las personas que lo necesitaran, fueran de uno u otro bando, pues el comité no era confesional. Finalmente se decidió que el Comité enviaría el dinero a través de la Cruz Roja. ${ }^{32}$

Como el American Commitee acudía a la Cruz Roja y no a la jerarquía española, la revista America creó otra asociación, la American Spanish Relief Fund, en mayo de 1937. El 5 de julio, Edward J. Ferger, sacerdote y escritor, se entrevistó en Pamplona con el cardenal Isidro Gomá. Conversaron durante dos horas. El Cardenal estaba interesado en conocer qué sabían los católicos americanos sobre la guerra y cuál iba a ser su ayuda. ${ }^{33}$ Ferger aseguró que le llegarían ayudas a través de la American Spanish Relief Fund. Esta institución iba a coordinar la respuesta católica norteamericana a las necesidades económicas de España. ${ }^{34}$ En septiembre el cardenal Gomá recibió 2.000 dólares para que fuesen distribuidos entre las familias de los niños de Bilbao, que habían salido del país antes de que entraran las tropas de Franco en la ciudad. ${ }^{35}$

Singular fue el caso del dinero que le llegó al cardenal Gomá a través de la Secretaría de Estado vaticana. Para asegurar que el dinero era recibido por la Iglesia española, algunos católicos de Estados Unidos enviaron sus aportaciones a la Santa Sede, y el mismo cardenal Pacelli contactó con Gomá. ${ }^{36}$

${ }^{30}$ Seis asociaciones estuvieron afiliadas al Comité: American Friends of Spanish Democracy; American League for Peace and Democracy (que había sustituido al American League Against War and Fascism); International Labor Defense; League for Industrial Democracy; Young Communist League (cf. nota de la conferencia de Merwin K. Hart en el encuentro de los American Patriots, 16-XII-1938, en ACUA, National Catholic Welfare Conference, Box 51 Folder 3).

${ }^{31}$ Las discrepancias entre America y Commonweal, cf. 1938. America 59: 292-293.

${ }^{32}$ Cf. 1937. "Comment". America: 55 y 170.

${ }^{33}$ Con anterioridad, el cardenal Gomá había alertado ante posibles iniciativas particulares; cf. AndrésGallego, J. y Pazos, A. M. Archivo Gomá: Documentos de la Guerra Civil. Madrid: Consejo Superior de Investigaciones Científicas, vol. VI, Documento 6-495 (en adelante, Archivo Gomá). En cambio, solicitó ayuda económica a diversos obispos, entre ellos los de Boston, Filadelfia y Chicago (cf. Carta del cardenal Gomá al cardenal O'Connell, Toledo, 15-XI-1936, en Archivo Gomá, Documento D-180).

${ }^{34}$ Cf. Ferger E. J. 1937. "Moors and Clergy Loyal to Nationalists". America: 392.

${ }^{35}$ Cf. 1937. "Comment". America: 555.

${ }^{36}$ Ver, por ejemplo, cartas del cardenal Pacelli al cardenal Gomá, Ciudad del Vaticano, 16-IX-1937, en Archivo Gomá, Documento 7-417 y Documento 7-418. 
Hubo otras aportaciones, numerosas y de carácter particular, aunque fuesen unos pocos dólares enviados por carta al Arzobispo de Toledo. ${ }^{37}$

No hubo ayuda militar ni reclutamiento de personal por parte de los católicos americanos. En octubre de 1938, un sacerdote, redactor del diario The Catholic Columbian, preguntó a mons. Ready sobre este particular. La respuesta de Ready fue clara. Los obispos no colaboraban en esas actividades. Además, le recordó que los representantes del Gobierno nacional en Estados Unidos eran escrupulosos a la hora de no infringir los acuerdos que tenían con el Departamento de Estado norteamericano. ${ }^{38}$

\section{RELACIÓN CON LAS AUTORIDADES CIVILES}

Tanto el Presidente como el Congreso de los Estados Unidos mantuvieron un férreo embargo en el envío de armas a España. Un año antes del inicio de la guerra civil, en agosto de 1935, el Congreso de Estados Unidos había aprobado la "Neutrality Act", que aseguraba la neutralidad en los conflictos internacionales o civiles. La neutralidad era consecuencia de la amargura por los resultados conseguidos en la primera guerra mundial, y reforzaba el tradicional aislacionismo de Estados Unidos.

Al comenzar la guerra civil, el Presidente Franklin D. Roosevelt reafirmó su compromiso de no interferir en los asuntos internos de otros países. El 8 de enero de 1937, el Congreso aprobó la "Spanish Embargo Act", ley con la que sancionaba legalmente la posición de neutralidad. Meses más tarde, el 1 de mayo, el Congreso revisó la "Neutrality Act", añadiendo una enmienda que prohibía el envío de armas y municiones a países en guerra civil o con guerras internacionales. Esta enmienda apuntaba, en primer lugar, al caso español. ${ }^{39}$

Estas circunstancias, que favorecían a las tropas de Franco, fueron aprovechadas por los obispos americanos. A través de informaciones que le habían llegado al cardenal de Nueva York, Patrick Hayes, la NCWC supo que se estaban reclutando tropas en suelo norteamericano de modo clandestino para enviarlas a luchar al lado de los republicanos españoles. Denunciaron el hecho ante el Departamento de Justicia, pues la ley americana prohibía reclutar ciudadanos en Estados Unidos para que luchasen en las fuerzas armadas de un país extranjero. La Administración norteamericana fue dando largas al asunto, aduciendo que la ley no prohibía a un ciudadano norteamericano viajar al extranjero y pelear de modo voluntario en un ejército. Un año más tarde, el Gobierno informó a la NCWC que las personas de la Brigada Abraham Lincoln habían actuado de acuerdo con la libertad de movimientos de que gozaban los ciudadanos norteamericanos. ${ }^{40}$

${ }^{37}$ Pueden verse varias cartas en Archivo Diocesano de Toledo (en adelante ADT), Pontificados. Fondo cardenal Isidro Gomá y Tomás, caja 8 , s.c.

${ }^{38}$ Carta de Michael J. Ready a Herman E. Mattingly, Washington, 22-IX-1938, en ACUA, Collection 10, Box 135, Folder 5.

${ }^{39}$ Para las vicisitudes del mantenimiento del embargo, cf. Traina R. P. 1968. American Diplomacy and the Spanish Civil War. Bloomington-Londres: Indiana University Press. Sobre la relación entre los católicos norteamericanos y la política del Presidente Roosevelt acerca de la guerra civil española, cf. Flynn G. Q. 1976: 29-55.

${ }^{40}$ Memorandum, conversación entre Michael J. Ready y Edward J. Heffron con Brian McMahon, Adjunto al Fiscal General de Estados Unidos, Washington, 10-II-1938, en ACUA, National Catholic Welfare Conference, Box 51 Folder 1. 
Otro punto en la agenda de la NCWC fue la relación con las autoridades civiles españolas. ${ }^{41}$ En febrero de 1937, Montavon se trasladó a Nueva York para encontrarse con el embajador de la República española, Fernando de los Ríos. ${ }^{42}$ Hablaron en un tono cordial sobre la guerra hasta que trataron acerca de los católicos que «han levantado el argumento de la religión en España con la finalidad de promover sus egoístas intereses políticos». ${ }^{43}$ Montavon aprovechó el encuentro para intervenir ante la embajada española a favor de los agustinos de El Escorial que habían sido encarcelados. $^{44}$

Montavon se entrevistó con Juan Francisco de Cárdenas, representante de la Junta de Defensa Nacional en Estados Unidos, que residía en Washington. ${ }^{45}$ De Cárdenas había llegado a América con cartas de presentación, firmadas por el cardenal Gomá, para los cuatro cardenales estadounidenses: Patrick J. Hayes, de Nueva York; George W. Mundelein, de Chicago; William H. O'Connell, de Boston; y Dennis J. Dougherty, de Filadelfia.

\section{LECTURA NORTEAMERICANA DE LA CARTA COLECTIVA}

La toma de Bilbao en el mes de junio de 1937 fue vista como un momento decisivo en el desenlace de la guerra, cada vez más favorable a Franco. ${ }^{46}$ Las publicaciones comenzaron a preguntarse por el futuro de España. Parecía evidente que Franco comenzaría con un periodo de dictadura. Quedaba la incertidumbre sobre el regreso de la monarquía después de algunos años. Este hecho fue un acicate para los republicanos españoles solicitaran más ayuda económica y militar.

Después de un año de conflicto, en el verano de 1937 las posturas sobre la guerra habían quedado definidas en Estados Unidos. Los católicos y su prensa afín apoyaban la causa nacional, mientras que los protestantes y la prensa liberal defendían a los republicanos. En el mes de septiembre llegó con una sorpresa. Los obispos españoles publicaron una carta pastoral colectiva, fechada el día 1

${ }^{41}$ Ver una interesante comparación entre los dos representantes españoles, el primero republicano y el segundo nacional, en Rey García, M. 1996. "Fernando de los Ríos y Juan F. de Cárdenas: dos embajadores para la guerra de España (1936-1939)". Reden 11: 129-149.

${ }^{42}$ El socialista y catedrático de derecho Fernando de los Ríos (1879-1949) fue embajador de España en Estados Unidos desde septiembre de 1936 hasta abril de 1939. Durante la Segunda República había sido ministro en los Gobiernos de Manuel Azaña. Cf. Ruiz-Manjón, O. 2007. Fernando de los Ríos: un intelectual en el PSOE. Madrid: Editorial Sintesis.

43 «He condemns those Catholics who he claims have raised the religious issue in Spain for the purpose of promoting their own selfish political interests» (Memorandum de William F. Montavon a Michael J. Reday, Washington, 11-II-1937, en ACUA, National Catholic Welfare Conference, Box 50 Folder 22.

${ }^{44}$ Cf. Memorandum de William F. Montavon a Michael J. Reday, Washington, 11-II-1937, en ACUA, National Catholic Welfare Conference, Box 50 Folder 22.

45 Juan Francisco de Cárdenas Rodríguez (1881-1966) había sido embajador de España en los Estados Unidos entre 1932 y 1934. Al comenzar la guerra civil, apoyó al Movimiento nacional, y fue enviado por Franco a Estados Unidos. En 1939 fue nombrado embajador de España en aquel país. Cf. Cortada, J. W. 1982. Historical dictionary of the Spanish Civil War, 1936-1939: 105-106. Westport: Greenwood Press.

46 «I do not see how he can possibly lose now», afirma un corresponsal de America en el mes de agosto (Ferger E. J. 1937. "Normalcy Restored to Bilbao with Advent of Franco". America 57: 416). 
y dirigida a todos los obispos del mundo. ${ }^{47}$ La carta estaba suscrita por cuarenta y tres obispos residenciales y cinco vicarios capitulares. ${ }^{48} \mathrm{Al}$ comienzo de la carta, los obispos agradecían a sus hermanos de otros países el apoyo que les habían manifestado. Al mismo tiempo, manifestaban su dolor por el desconocimiento de lo que ocurría. La propaganda había tergiversado las noticias sobre la situación de la guerra y sobre el papel que desempeñaba la Iglesia católica.

La carta subrayaba cinco ideas: primera, la Iglesia no había conspirado o provocado el conflicto: «La Iglesia no ha querido esta guerra ni la buscó»; ${ }^{49}$ segunda, en la zona republicana se había producido una persecución religiosa sin precedentes que coincidió con el Alzamiento: «una de las partes beligerantes iba a la eliminación de la religión católica en España»; ${ }^{50}$ tercera, la persecución estaba unida a la revolución: «la revolución comunista, aliada de los ejércitos del gobierno, fue, sobre todo, antidivina»; ${ }^{51}$ cuarta, la persecución condujo a la Iglesia a situase no tanto junto a los sublevados como detrás de ellos con el fin de salvar la vida: ${ }^{52}$ "no nos hemos atado con nadie -personas, poderes o instituciones- aun cuando agradezcamos el amparo de quienes han podido librarnos del enemigo que quiso perdernos, y estemos dispuestos a colaborar, como Obispos y españoles, con quienes se esfuercen en reinstaurar en España un régimen de paz y justicia»: ${ }^{53}$ quinta, se pedía al movimiento nacional que reconstruyese el país de acuerdo con el ser tradicional español: «que resurja el espíritu nacional con la pujanza y la libertad cristiana de los tiempos viejos»». ${ }^{54}$

La carta señalaba el comunismo como el verdadero origen de la guerra y el mal que se combatía. Había surgido, como reacción, un movimiento religioso, dividiéndose España en dos tendencias: «la espiritual, del lado de los sublevados, que salió a la defensa del orden, la paz social, la civilización tradicional y la patria, y muy ostensiblemente, en un gran sector, para la defensa de la religión; y de la otra parte, la materialista, llámese marxista, comunista o anarquista, que quiso sustituir la vieja civilización por la novísima "civilización" de los soviets rusos». ${ }^{55}$

La carta colectiva llegó en seguida a Estados Unidos. William F. Montavon la tradujo y la NCWC la publicó en inglés. ${ }^{56}$ Todos los semanarios diocesanos norteamericanos se hicieron eco. Se deseaba que muchos católicos americanos la leyeran. ${ }^{57}$ Además, llegaron copias desde España, enviadas a petición de algunos obispos o por iniciativa de Alfonso de Zulueta, sacerdote residente en Oxford.

${ }^{47}$ 1937. Carta Colectiva de los Obispos españoles a los de todo el mundo con motivo de la Guerra en España. Pamplona: Gráficas Bescansa.

${ }^{48}$ Dos obispos no firmaron voluntariamente la carta: el arzobispo de Tarragona, Francesc Vidal i Barraquer, y el obispo de Vitoria, Mateo Múgica. Los dos residían entonces en Roma.

${ }^{49}$ Carta Colectiva de los Obispos españoles a los de todo el mundo con motivo de la Guerra en España: 7.

${ }^{50}$ Ibídem: 8.

${ }^{51}$ Ídem.

${ }^{52}$ Cf. Redondo, G. 1993. Historia de la Iglesia en España. 1931-1939, tomo II, "La Guerra Civil (19361939)": 315. Madrid: Rialp.

${ }^{53}$ Carta Colectiva de los Obispos españoles a los de todo el mundo con motivo de la Guerra en España: 8.

${ }^{54}$ Ibídem: 26.

${ }^{55}$ Ibídem: 14

${ }^{56}$ Varias copias impresas de la carta, editadas por la NCWC, pueden verse en ACUA, Collection 10, Box 228, Folder 31.

${ }^{57}$ 1937. "Comment". America 57: 530. 


\section{LA RÉPLICA A LOS CIENTO CINCUENTA PROTESTANTES}

La carta colectiva abrió una nueva etapa en las relaciones, no precisamente amistosas, entre los protestantes y los católicos. El 4 de octubre apareció publicada en el New York Times una "carta abierta" dirigida a la jerarquía católica española. La firmaban ciento cincuenta protestantes, clérigos, educadores y laicos. Según las informaciones que recibieron los obispos, el North American Committee to Aid Spanish Democracy había colaborado en la redacción de la "carta abierta". ${ }^{58}$

Los protestantes americanos criticaban cuatro ideas que, según ellos, estaban presentes en la carta colectiva y eran inadmisibles: a) aprobar la violencia como solución política; b) rechazar la Segunda República; c) estigmatizar el sistema constitucional; d) condenar las instituciones democráticas, la libertad de culto y la separación de la Iglesia y el Estado. Los obispos españoles defendían ideas de épocas pasadas: «es difícil creer que esta carta pastoral ha sido escrita en el siglo $\mathrm{XX} \gg{ }^{59}$.

Se exageraba el papel de la Unión Soviética en la guerra, mientras que no se decía nada sobre «la ayuda dada a Franco por los nazis, los italianos y los moros». ${ }^{60}$ Por último, la "carta abierta" de los protestantes arrojaba el guante: «Esta carta pastoral, por ejemplo, ¿refleja los puntos de vista políticos de la Iglesia Católica en América?» ${ }^{61}$

Michael Ready, secretario general de la NCWC, no rehusó el envite. Veinticuatro horas después de haberse publicado la "carta abierta", la prensa recibió una declaración del Prelado católico. Según parece, el borrador de la respuesta fue escrito por Montavon y corregido -y firmado- por Ready. ${ }^{62}$ Preocupaba a Mons. Ready que un grupo, entre los que había ministros de la religión, defendiera a un gobierno relacionado «con el asesinato de miles de sacerdotes de Dios y de santas mujeres; que ha destrozado miles de iglesias; que es abiertamente ateo y anti-Cristo; y que ha eliminado y prohibido el culto público de la religión en aquellos lugares de España que controla. Cuando se insinúa, además, que los católicos americanos se oponen a los conceptos democráticos básicos, debe hacerse una réplica» ${ }^{63}$.

${ }^{58}$ Cf. carta de John V. Hinkel a Michael J. Ready, Nueva York, 5-X-1937, en ACUA, National Catholic Welfare Conference, Box 50 Folder 22. Hinkel era periodista del New York Times.

59 «It is hard to believe that this pastoral letter was written in the Twentieth Centrury» (4-X-1937. "An Open Letter on the Spanish Hierarchy”. New York Times: 12).

${ }^{60}$ «Yet the Spanish prelates do not so much as have one word about the aid given Franco by the Nazis, the Italians and the Moors» (ibídem). (ibídem).

${ }^{61}$ «Does this pastoral letter, for example, reflect the political views of the Catholic Church in America?»

${ }^{62}$ En el archivo de ACUA hay un escrito de Rusell Palmer, periodista protestante, partidario de Franco, que había visitado España durante el verano de 1937 y grabó numerosas imágenes. Fue testigo de muchos de los sucesos que aparecen en la carta de los 150 protestantes, y señala que esa carta presenta como reales algunos hechos que no son imputables al Ejército nacional (cf. carta de Frank A. Hall a mons. Ready, con el escrito de Rusell Palmer adjunto, Washington 12-XI-1937, en ACUA, National Catholic Welfare Conference, Box 50 Folder 23).

63 «Grave concern, however, must be felt when such a group, including as it does many ministers of religion, undertakes to defend a regime red-handed with the murder of thousands of priests of God and holy women; which has destroyed thousands of churches; which is openly atheistic and anti-Christ, and which has crushed and forbidden the public practice of religion in those portions of Spain which it controls. When, in addition, the public insinuation is made that American Catholics oppose basic democratic concepts, reply must be made» (6-X-1937. New York Times: 6). 
Ready explicaba que la jerarquía española hablaba por sí misma y, por tanto, los puntos de vista políticos que allí aparecían eran los españoles. Rebatía, después, los cuatro puntos de la "carta abierta" de los protestantes: a) la nación española había recurrido a las armas porque no tuvo más posibilidades si deseaba sobrevivir frente al caos; b) los obispos españoles rehusaban adherirse a una forma de gobierno determinada; c) era una guerra entre el comunismo y los principios de España como nación; d) la Constitución de 1931 suprimió a los jesuitas y prohibió la enseñanza a las órdenes religiosas, confiscó propiedades a la Iglesia, implantó el divorcio y socializó la propiedad privada. En su conclusión, Ready ponía el ejemplo de un grupo de protestantes ingleses que habían establecido un comité para cooperar con la Iglesia católica, de modo que formasen un frente común frente al comunismo.

La réplica fue muy comentada. El secretario general de la NCWC recibió numerosas cartas de apoyo, comenzando por el Cardenal de Nueva York ${ }^{64}$. Setenta y tres españoles residentes en esa ciudad le enviaron un escrito de agradecimiento. ${ }^{65}$

Sin duda, la réplica marcó un cambio de táctica en la NCWC. Si hasta entonces Montavon había sido el representante de la jerarquía en los medios de comunicación, ahora era el Secretario de la conferencia de obispos quien tomaba las riendas y pasaba a ser el portavoz de los obispos en la opinión pública norteamericana acerca de la guerra civil española. Ready salía a la palestra. Pensaba que debía hacerlo. Ya no se trataba sólo de analizar el conflicto español y, en su caso, mostrar la solidaridad con los hermanos del otro lado del Atlántico. Ahora había que proteger a los católicos norteamericanos frente a las infiltraciones comunistas.

Unos días más tarde, Francis X. Talbot, jesuita y director del semanario America, reunió las firmas de ciento setenta y cinco católicos de reconocido prestigio y publicó una carta a favor de los obispos españoles. ${ }^{66}$ Talbot se preguntaba si los ciento cincuenta protestantes representaban a todos los protestantes americanos; si lo eran, su carta constituía una muestra más de la intolerancia protestante hacia el catolicismo; si no los representaban, pedía un pronunciamiento oficial del mundo protestante.

Según Talbot, los obispos españoles no se habían opuesto a la República ni siquiera cuando se aprobó la Constitución de 1931 que subordinaba, en algunos aspectos, la Iglesia al Estado; tampoco lo hicieron cuando se aprobaron leyes tan conflictivas como la prohibición de enseñanza a los religiosos; ni siquiera atacaron a la República cuando, en julio de 1936, se sublevó Franco. Pero, a la vista del asesinato indiscriminado de sus sacerdotes en una de las zonas en guerra, apoyaron necesariamente a la otra. Eran los protestantes los que tenían que definirse: «los protestantes americanos, ¿aceptan y aprueban un régimen gubernamental que ha llevado a cabo una dura persecución de la religión cristiana desde febrero de 1936? ¿Aprueba el protestantismo a un régimen que está compuesto predominantemente por radicales socialistas, comunistas, sindicalistas y anarquistas?». ${ }^{67}$

${ }^{64}$ Cf. Carta de John J. Casey, secretario del cardenal Hayes, a Michael J. Ready, New York, 6-X-1937, en ACUA, Collection 10, Box 135, Folder 4.

${ }^{65}$ Cf. Carta de José Ajuría y otros 72 firmantes a Michael J. Ready, Nueva York, 12-X-1937, en ACUA, National Catholic Welfare Conference, Box 50 Folder 22.

${ }^{66}$ Cf. 14-X-1937. "175 Catholics back aid to Insurgents". New York Times: 20.

${ }^{67}$ «Do American Protestants accept and endorse a governmental regime that has carried on a ruthless persecution of the Christian religion since February, 1936? Does American Protestantism endorse a regime that is composed predominantly of radical Socialists, Communists, Syndicalists and Anarchists?» (ibídem).

Hispania Sacra, LXIV Extra I, enero-junio 2012, 315-341, e-ISSN: 1988-4265, doi: 10.3989/hs.2012.033 


\section{LA CERCANÍA CON LOS OBISPOS ESPAÑOLES}

Los obispos de todo el mundo enviaron a sus homólogos españoles cartas en las que agradecían la carta colectiva y manifestaban su dolor ante la persecución religiosa y la incomprensión sobre las causas de la guerra. La opinión de que el comunismo estaba detrás de la guerra era general.

La carta norteamericana llegó el 20 de noviembre de 1937. Ese día tuvo lugar en Washington la clausura del General Meeting que celebraban anualmente los obispos americanos. Ochenta y dos prelados se encontraron en la capital. Mons. Ready preparó para el encuentro dos borradores con sendas declaraciones que se podían aprobar en la reunión: una estaba dirigida a los obispos alemanes, y otra a los obispos españoles. Los obispos americanos discutieron en qué términos podían referirse a la guerra española, pues no les resultaba sencillo adoptar una resolución que no fuese interpretada en términos políticos. ${ }^{68}$

Finalmente ratificaron las dos declaraciones, fechadas el 18 de noviembre, que llevaban las firmas del presidente y del secretario de la NCWC, el cardenal de Filadelfia, Dennis J. Dougherty, y el obispo de Charleston, Emmet M. Walsh. En la carta a los obispos españoles, los americanos les daban su apoyo. No decían nada sobre el régimen de gobierno en la zona nacional. Los obispos denunciaban que «una propaganda artera, usada maliciosamente por aquellos que fomentan el ateísmo y el caos, ha obscurecido la realidad de los hechos que han tenido lugar». ${ }^{69}$ Los asesinos se habían presentado como defensores de los derechos humanos, algo que causaba en los obispos americanos «profundo horror, porque aceptamos como axioma la libertad de conciencia y de palabra». ${ }^{70}$ Los prelados manifestaban la convicción de que los católicos españoles «tratan de fomentar y convertir en hermosa realidad los principios sociales de las encíclicas de nuestro Santo Padre» ${ }^{71}$ y recordaban su compromiso de ser leales a los principios democráticos de Estados Unidos.

El cardenal Gomá agradeció la carta, el primer y único pronunciamiento oficial del episcopado norteamericano sobre la guerra civil española. ${ }^{72}$ Isidro Gomá subrayó en su respuesta que habían sufrido una feroz persecución y una "propaganda que pretendía hacer pasar a la Iglesia por enemiga del pueblo presentando también a nuestros gloriosos e indefensos mártires como agresores». ${ }^{73}$ La misiva del cardenal Gomá fue traducida y enviada desde la NCWC a los obispos americanos y a la prensa católica. $^{74}$

${ }^{68}$ Cf. Carta de Samuel A. Stritch, arzobispo de Milwaukee, a Michael J. Ready, Milwaukee, 8-XI-1937, en ACUA, National Catholic Welfare Conference, Box 50 Folder 23.

${ }^{69}$ El texto original, se encuntra en ACUA, National Catholic Welfare Conference, Box 50 Folder 23. La traducción al castellano puede verse en Archivo Gomá, Documento 8-306.

70 Ídem.

71 Ídem.

72 El delegado apostólico en Estados Unidos, Amleto Giovanni Cicognani, se encargó de traducirla al castellano y de enviarla al cardenal Gomá. Puede verse la correspondencia en ADT, Pontificados. Fondo cardenal Isidro Gomá y Tomás, caja 25, s.c.

73 Carta de Isidro Gomá a Dionisio Dougherty, Pamplona, 29-XII-1937, en ACUA, National Catholic Welfare Conference, Box 50 Folder 23.

${ }^{74}$ Cf. carta del cardenal Dennis Joseph Dougherty a Amleto Giovanni Cicognani, delegado apostólico en Estados Unidos, Filadelfia, 18-II-1938, en ACUA, National Catholic Welfare Conference, Box 50 Folder 23. 


\section{LA RESPUESTA A LOS SESENTA CONGRESISTAS}

1938 fue un año de gran combate en la prensa norteamericana sobre los temas relacionados con España. El primer asunto saltó a la palestra el 31 de enero, día en que los periódicos publicaron un mensaje de «good wishes», ${ }^{75}$ enviado por sesenta congresistas al Parlamento español con ocasión de la sesión que iba a tener lugar en Barcelona el 1 de febrero. El Parlamento no había reunido desde el mes de octubre del año anterior.

Los congresistas decían que la reunión de sus homólogos españoles «reafirma su fe en el gobierno democrático. Nosotros, que amamos la libertad y la democracia por encima de todo, nos damos cuenta del significado de vuestra heroica y resuelta lucha para salvar las instituciones democráticas de vuestra joven república de sus enemigos de dentro y de fuera de España. Vuestra lucha ofrece un conmovedor ejemplo a todos los pueblos democráticos»». ${ }^{76}$

$\mathrm{Al}$ día siguiente, apareció en la prensa una nueva declaración oficial de Ready. Era sorprendente que los congresistas mostrasen su solidaridad «con un gobierno que tiene totalmente prohibido el ejercicio de la religión en el territorio que gobierna». ${ }^{77}$ Había muchos interrogantes no aclarados sobre el Gobierno republicano de Barcelona: si había sido elegido debidamente en febrero de 1936, si era el sucesor legal del Gobierno de Madrid, si podían tildar de fascistas a sus adversarios... Lo que no cabía duda, según Ready, era que el Gobierno actual y sus predecesores «habían sido responsables de la tortura y asesinato de miles de obispos y sacerdotes y religiosas, de la desacralización y destrucción de cientos de iglesias y santuarios, y de la total negación de la libertad religiosa» ${ }^{78}$.

Polemizaba Ready diciendo que el "saludo democrático" de los congresistas norteamericanos no habría sido posible si fuesen parlamentarios en España, pues allí la libertad de prensa había sido suprimida. Lanzaba, además, dos cuestiones a la opinión pública. La primera provenía de los informes recibidos. Se refería a quiénes eran los responsables de la petición de firmas para ese mensaje; concretamente, se preguntaba acerca del papel que había jugado la embajada de España: «uno se pregunta si una embajada se ha transformado en una agencia de propaganda ${ }^{79}$. En segundo lugar, se congratulaba que hubiesen firmado el mensaje sólo sesenta congresistas, lo que suponía el once por ciento del total, compuesto por quinientos treinta y un senadores y representantes.

Varios de los sesenta congresistas eran católicos o, al menos, conocidos por la NCWC. Durante los días siguientes, el departamento de prensa de la NCWC se encargó de hablar con ellos. Una semana

\section{${ }_{75}^{75}$ 31-I-1938. "60 in U.S. Congress hail Spain's Cortes”. New York Times: 6.}

${ }^{76}$ «For you to meet again in the face of the trying and tragic circumstances of the present demonstrates that the Spanish people and their representatives stand firm in their faith in democratic government. We, who cherish freedom and democracy above all else, realize the significance of your heroic and determined fight to save the democratic institutions of your young republic from its enemies both within and without Spain. Your struggle sets a stirring example to all democratic peoples» (ídem).

${ }_{77}$ «with a government which has absolutely proscribed the exercise of religion in the territory which it governs» ("Signing by 60 Congressmen of Note Lauding Spain Reds Scored by Monsignor Ready", N.C.W.C. News Service, 1-II-1938, en ACUA, National Catholic Welfare Conference, Box 51 Folder 1).

${ }^{78}$ «the Barcelona Government and its predecessors have been responsible for the torture and murder of thousands of Bishops and priests and nuns, the desacration and destruction of hundreds of churches and shrines, and the complete denial of religious freedom» (ídem).

${ }^{79}$ «one may well wonder whether an embassy has been turned into a propaganda "pressure" agency» (ídem).

Hispania Sacra, LXIV Extra I, enero-junio 2012, 315-341, e-ISSN: 1988-4265, doi: 10.3989/hs.2012.033 
más tarde, tres congresistas se retractaron, diciendo que habían firmado la carta de modo precipitado; y otros veintiséis afirmaron que no estaban a favor del actual Gobierno de Barcelona y que se les había confundido, pidiéndoles sólo su apoyo a la democracia parlamentaria y al poder constituido, sin contarles pormenores del caso español ${ }^{80}$.

Cerrada la polémica de los sesenta congresistas, Ready se quejó a un amigo de la propaganda por lo que tenía de falsedad y mentira: «La actitud de la prensa acerca de la situación en España es muy descorazonadora. Es necesaria una revisión constante de los periódicos y revistas si queremos tener éxito en el combate con ese prejuicio» ${ }^{81}$. Ready había decidido explicar a los norteamericanos, católicos o no, políticos o ciudadanos corrientes, la verdad sobre la guerra.

En marzo de 1938, los periódicos dieron la noticia del bombardeo de Barcelona, en el que murieron civiles. El Secretario de Estado, Cordell Hull, lo condenó. ${ }^{82}$ Sus palabras manifestaban el aprecio de la Administración Roosevelt hacia el Gobierno republicano y, para algunos, abrían la esperanza de que se enviase a España ayuda económica o, incluso, militar.

Michael Ready se sintió impelido a hacer una nueva declaración pública acerca de la guerra civil española. Era la tercera en ocho meses. El Prelado afirmó que el bombardeo de población civil era algo condenable y, desde luego, no se justificaba por razones militares. En este sentido, apoyaba las palabras de Hull. Lo que no entendía era por qué el Secretario de Estado guardó un «completo silencio cuando, también en España, no cientos sino miles de sacerdotes y religiosos fueron asesinados de modo cruel. Esos asesinatos ni siquiera fueron justificados por razones militares; fueron cometidos por el simple hecho de que las víctimas eran clérigos» ${ }^{83}$.

El cardenal de Nueva York, Patrick Hayes, y el de Boston, William H. O'Connell, afirmaron en la prensa que los bombardeos eran una maniobra militar del general Franco y que no tenían como fin el asesinato de civiles. Mons. Hayes añadió que algunos medios de comunicación apoyaban sólo a la parte la republicana y que faltaban pruebas sobre esos ataques indiscriminados. ${ }^{84}$ Estas declaraciones tensaron más la cuerda entre los protestantes y los católicos, pues un grupo de obispos protestantes pidieron a los católicos que influyeran ante Franco para que no hiciera más bombardeos, y los católicos contestaron que en Barcelona existían objetivos militares que podían ser atacados. ${ }^{85}$

\section{EL VIAJE A ESPAÑA DE LOS PRELADOS NORTEAMERICANOS}

80 "Half Spain Greeting Signers Deny They Favor Leftists; 3 Repudiate; Trickery Charged", N.C.W.C. News Service, 7-II-1938, en ACUA, National Catholic Welfare Conference, Box 51 Folder 1.

${ }^{81}$ «The attitude of the press on regard to the situation in Spain is most discouraging. A constant check-up on the papers and magazines is necessary if we are to succeed in combating such prejudice» (carta de Michael J. Ready a I. Moore, Washington, 25-II-1938, en ACUA, Collection 10, Box 135, Folder 5).

${ }^{82}$ Cf. 23-III-1938. The Washington Post: 1.

83 «Mr. Hull's complete silence when, also in Spain, not hundreds but many thousands of priests and Religious were wantonly murdered. These killings had back of them not even the attempted justification of military exigencies; they were perpetrated on the simple basis of the victims being religious» ("Sec. Hull's Silence as Reds Slew Spain Priests Deplored”, N.C.W.C. News Service, 23-III-1938, en ACUA, National Catholic Welfare Conference, Box 51 Folder 1). Tribune.

${ }^{84}$ Cf. 24-III-1938. "Cardinal Hayes Says He Prays For Franco to Win War in Spain”. New York Herald

${ }^{85}$ Cf. Tusell, J. y García Queipo de Llano, G. 1993: 340. 
Entre abril y mayo de 1938, el embargo de envío de armas a España entró de nuevo en el debate político. A principios de mayo, la prensa divulgó la noticia del levantamiento del embargo ${ }^{86}$. Según parece, el rumor se había alimentado porque el Presidente de Estados Unidos había comentado a algunos congresistas que deseaba la victoria de los republicanos. Quizá detrás de esta actitud estaba el creciente temor de Roosevelt hacia el poder militar de Alemania, que había ocupado Austria en marzo y amenazaba a Checoslovaquia. Además, y según las encuestas, la mayoría de los norteamericanos era favorable a los republicanos. ${ }^{87}$ Pero, unos días más tarde, todo quedó suspendido. El 13 de mayo, el comité para las relaciones exteriores del Senado rechazó una resolución que hubiese planteado el caso al Congreso. ${ }^{88}$

Durante la primavera de 1938, tuvo lugar la visita a Estados Unidos de José Bergamín, que había sido director de la revista Cruz y Raya durante la Segunda República y era reconocido como católico influyente. El viaje fue pagado por el Medical Bureau and North American Committee to Aid Spanish Democracy. Poco después, el sacerdote irlandés Michael O'Flanagan hizo una nueva gira por el país hablando a favor de la República, a la vez que criticaba a los obispos norteamericanos porque daban su apoyo a los españoles. ${ }^{89}$ Esta propaganda se contrarrestó con la noticia de que el 30 de junio el Papa había aceptado las credenciales del embajador José María Yangüas, pues Franco dominaba ya dos tercios del territorio español, la Santa Sede necesitaba negociar con el Gobierno de Burgos, y además habían fracasado las gestiones del republicano y católico Manuel de Irujo para conseguir una progresiva libertad de culto en la zona republicana.

Algunos prelados norteamericanos decidieron visitar España con el fin de obtener información de primera mano. El verano parecía especialmente favorable. El secretario general de la NCWC, Michael Ready, tenía que acudir a Roma para entrevistarse con varias personas en el Vaticano y, a su regreso, deseaba pasar por España. Por su parte, Karl J. Alter, obispo de Toledo, Ohio, iba a estar presente en el Congreso Eucarístico de Budapest a finales de mayo y después quería visitar al cardenal Gomá. Finalmente, John M. Gannon, obispo de Erie, Pensilvania, pasaría por España en el mes de septiembre.

Los visados para los viajes, solicitados por los prelados en la Secretaría de Estado norteamericana, fueron concedidos sin grandes dificultades. ${ }^{90}$ Después cada uno pidió por su cuenta un visado de entrada en la zona nacional. Juan F. de Cárdenas, representante del Gobierno Nacional, les dio cartas de presentación e informó al ministro de Asuntos Exteriores, Francisco Gómez Jordana, al Jefe del Servicio Nacional de Prensa y al cardenal Gomá. ${ }^{91}$ Tanto la Iglesia católica española como el Gobierno del general Franco pusieron todos los medios para recibir y agasajar del mejor modo posible a tan ilustres invitados. Serían estupendos embajadores de la causa nacional en Estados Unidos y, además, podrían conseguir dinero de los católicos norteamericanos cuando acabase la guerra civil.

\footnotetext{
${ }^{86}$ Cf. 5-V-1938. “Roosevelt Backs Lifting Arms Embargo on Spain”. New York Times: 1.

${ }^{87}$ Cf. carta de Grafton S. Wilcox, editor de Herald Tribune, a Paul R. Martin-Dillon, director de la Oficina de Información de la N.C.W.C., Nueva York, 24-XII-1938.

${ }^{88}$ Cf. Traina R. P. 1968: 226.

${ }^{89}$ Michael O'Flanagan había estado con anterioridad en Estados Unidos, en el verano de 1937, hablando a favor del Gobierno republicano. Sobre estas dos visitas, cf. Sánchez J. M. 1992: 213-215.

${ }^{90}$ La documentación para el caso de mons. Ready, que incluye la correspondencia con el embajador de la zona nacional, Juan F. de Cárdenas, se puede ver en ACUA, National Catholic Welfare Conference, Box 51 Folder 2

${ }^{91}$ Cf. Archivo Gomá, Documento 10-123.
} 
Mons. Ready solicitó por carta el permiso necesario para viajar a la zona republicana al embajador de la República, Fernando de los Ríos. No tuvo respuesta.

El sábado 23 de julio, Mons. Karl J. Alter y Mons. Ready llegaron a Salamanca en un avión procedente de Lisboa. Según declararon a la prensa, acudían a España para «estudiar los variados problemas de ayuda surgidos en la trágica guerra que se libra ahora en el territorio». ${ }^{92}$ En Salamanca les recibió el Gobernador, Jesús Ferrer, y el general José Millán Astray. Después de visitar al obispo, Enrique Pla y Daniel, comenzaron una gira que les llevó a Sevilla, Valladolid, Burgos, Santander, Pamplona y Zaragoza. Se interesaron especialmente por el Auxilio Social, el sistema de ayuda social creado durante la guerra que alimentaba, según afirmaban, a más de 70.000 niños diariamente. Durante la visita fueron acompañados por Pablo Merry del Val, colaborador de José Antonio Giménez Arnau en la Jefatura de Prensa y Propaganda del Ministerio del Interior.

El 1 de agosto Mons. Alter hizo su última escala en la ciudad de Toledo acompañado por su secretario particular. ${ }^{93}$ El cardenal Gomá les recibió con todos los honores. La ciudad, comenzando por el pleno del ayuntamiento, también se volcó con sus huéspedes. «Aquí es fácil mover a la gente para estas ocasiones», ${ }^{94}$ comentó el Cardenal. En la recepción, Gomá dijo a Alter: «cuando regreséis a vuestra Patria decid a la noble gente de vuestro país lo que habéis visto. Decidles que en España nos batimos contra la barbarie de fuera, que se ha solidarizado con la de nuestro suelo. Decidles que no luchamos para nosotros, sino por la causa de la gran civilización cristiana». ${ }^{95}$ Mons. Alter respondió en latín, pues no hablaba castellano. Refirió la buena impresión que le había causado su visita, se alegró de que se luchara contra «el enemigo terrible de la civilización», ${ }^{96}$ el comunismo, e invitó a Gomá para que acudiera a Toledo, Ohio, y asistiera a la consagración de la nueva catedral.

El 7 de agosto, Mons. Ready estaba de regreso en Estados Unidos. Llegaba con una idea clara: si deseaban defenderse en Estados Unidos frente al comunismo debían defender el cristianismo en España. A este objetivo, al que desde 1936 se había dedicado desde la NCWC, se entregaría con renovadas energías. Ante los medios de comunicación que cubrieron su llegada, Reddy declaró que Estados Unidos había sido engañado: «Para mí, los reportajes sobre los acontecimientos de España han sido un crimen contra la verdad». ${ }^{97}$ Sorprendía a Ready «el contraste que existe entre el estado actual de lo que ocurre en España y las viciosamente engañosas historias que se publican sobre esta situación en la prensa americana». ${ }^{98}$ «La así llamada campaña para la protección de la democracia es una

92 «The group are in Spain to study the varied problems of relief arising out the tragic war now being waged in that country» (Cable, N.C.W.C. News Service, Salamanca, 26-VII-1938, en ACUA, National Catholic Welfare Conference, Box 51 Folder 2).

${ }^{93}$ Cf. 1938. "El Sr. Obispo de Toledo (Ohio) ha visitado Toledo". Boletín Eclesiástico del Arzobispado de Toledo 10: 315-318.

${ }^{94}$ Carta de Isidro Gomá a José Cartañá, Toledo, 3-VIII-1938, en Archivo Gomá, Documento 11-155.

95 Gomá y Tomás, I. 1940. "Discurso en la recepción dada en Toledo a Mons. Alter", en Por Dios y por España: 522. Barcelona: Casulleras.

${ }^{96}$ 3-VIII-1938. ABC: 12. Sevilla.

97 «To me there has been a crime against truth in the reporting of events in Spain» ("Pope Hailed as Liberty's Champion by Msgr. Ready; Flays False Spain Reports", N.C.W.C. News Service, 8-VIII-1938, en ACUA, National Catholic Welfare Conference, Box 51 Folder 2).

98 «It is surprising the contrast that exists between the actual state of affairs in Spain and the viciously deceptive stories that are handed out on that situation in the America press» (idem). 
propaganda organizada, que procede principalmente de París donde, bajo el Gobierno de Blum, se le ha permitido existir y florecer libremente». ${ }^{99}$

Fuera de los teatros de operaciones militares, que no entraba a juzgar, Ready decía que el general Franco había «establecido un régimen civil del que podría estar orgulloso cualquier nación». ${ }^{100}$ Eso era, según el Secretario general, lo que había visto en numerosas ciudades de la Península Ibérica.

Para Ready, el enemigo seguía siendo el comunismo. «El intento de hacer de la revolución española una guerra ideológica o una batalla por la preservación de la democracia es una parte del programa comunista para engañar». ${ }^{101}$ La guerra era algo más que una batalla por la democracia, como decía la propaganda republicana: «Ellos entienden que la revolución debe ser lo que ahora es: un intento por parte del Comintern de borrar la civilización cristiana en España. Este programa aboga por la absoluta eliminación de la Iglesia en España, del mismo modo que fue eliminada en Rusia». ${ }^{102}$

Las réplicas a las declaraciones de Ready no se hicieron esperar. Los argumentos fueron los de siempre. Frente a un gobierno republicano y democrático se había alzado un dictador fascista; y la Iglesia católica americana estaba con el dictador. A finales de agosto, mons. Ready envió una nota a la prensa. Ironizó sobre la zona republicana, «aquella democrática tierra de libertad civil y religiosa» ${ }^{103} \mathrm{y}$ recordó que había solicitado un visado para acudir a esa zona de España y el embajador no se lo había concedido. En la zona nacional, en cambio, había tenido oportunidad de conversar con cientos de personas denominados por la prensa liberal "fascistas". No eran más que empresarios, trabajadores o profesionales sin filiación política alguna, contrarios al comunismo. En este sentido, «cien millones de americanos serían fascistas». ${ }^{104}$

Todavía en ese verano de 1938 se intentó otra maniobra, en este caso desde España. El cardenal Gomá envió misiones a varios países con el fin de que se expusiera a la jerarquía católica las necesidades españolas. Una de las misiones fue a Canadá. El cardenal Gomá, que ya había hablado con mons. Ready sobre el tema cuando éste estuvo en Toledo, le preguntó si era conveniente que la misión acudiese también a Estados Unidos, con la presencia añadida de algún católico americano que conociese bien la situación española como, por ejemplo, el padre Francis X. Talbot. ${ }^{105}$ Compondrían la misión dos sacerdotes y un laico: Luis de Despujol, secretario del cardenal Gomá; Manuel Graña,

99 «This so-called drive for the protection of democracy is organized propaganda, emanating chiefly from Paris, where, under the Blum government, it was permitted freely to exist and to flourish» (ídem).

100 «General Franco and his united people have established a civil regime of which any nation could be proud» (ídem).

101 «The attempt to make the Spanish revolution a war of ideology or a battle for the preservation of democracy, is a part of a communist program of deception» (ídem).

102 «They understand the revolution to be what it actually is -an effort on the part of the Comintern to liquidate the Christian civilization of Spain. This program calls for the absolute destruction of the Church in Spain, as they destroyed it in Russia» (ídem).

103 «in that democratic land of religious and civil freedom» (nota de prensa de N.C.W.C. News Service, 29-VIII-1938, en ACUA, National Catholic Welfare Conference, Box 51 Folder 2).

104 «a hundred million American "Fascists"» (nota de prensa de N.C.W.C. News Service, 29-VIII-1938, en ACUA, National Catholic Welfare Conference, Box 51 Folder 2).

${ }^{105}$ Cf. "De la conversación con Mgr. Ready", s/f, en ADT, Pontificados. Fondo cardenal Isidro Gomá y Tomás, caja 8 , s.c. 
antiguo redactor de El Debate; y Pablo Merry del Val, de la Jefatura de Prensa y Propaganda. ${ }^{106}$ Pero la misión tuvo que suspenderse dada la situación internacional creada por Alemania con los Acuerdos de Munich $^{107}$.

\section{LA LUCHA PARA MANTENER EL EMBARGO}

En septiembre de 1938, las Brigadas internacionales se retiraron de las zonas de combate. En noviembre, la Batalla del Ebro finalizó con la victoria de Franco. Sólo quedaba dar la puntilla al conflicto con la caída de Barcelona y de Madrid. La NCWC siguió con atención el envío de un barco con ayuda humanitaria, coordinado por el North American Committee to Aid Spanish Democracy y patrocinado por el Departamento de Trabajo. Temía que escondieran armas. Escribieron al congresista demócrata John W. McCormack, que era católico. McCormack envió una carta personal al Presidente Franklin D. Roosevelt. Y el Presidente le contestó que el Gobierno norteamericano iba a enviar a España un barco con ayuda humanitaria, a través de la Cruz Roja Americana. ${ }^{108}$ El 1 de noviembre, el carguero Erica Reed partió desde el puerto de Nueva York con destino a Valencia.

El 1 de diciembre tuvo lugar en la Academia de Música de Filadelfia un encuentro organizado por la Spanish Nationalist Relief Commitee, y dirigido por su Presidente, A. Hamilton Rice, de la Universidad de Harvard. Asistió el cardenal Dougherty junto con otros tres obispos y más de cuatro mil personas. Además de indicar que no estaba conforme con la actitud de la Iglesia protestante en Estados Unidos, calificó la contienda española como una «guerra mundial y santa de la cristiandad contra el ateísmo». ${ }^{109}$

Unas semanas más tarde, James H. Ryan, obispo de Omaha, Nebraska, y el sacerdote Maurice S. Sheehy se entrevistaron con el Presidente Roosevelt antes de un viaje que iban a realizar por Latinoamérica. El Presidente les dijo que muchas personas, también católicas, pensaban que la victoria de Franco era perjudicial para la paz mundial. Mons. Ryan respondió que la mayoría de los católicos americanos condenaban «el régimen de Barcelona por ser comunista y que ellos entendían la situación en España como una guerra del cristianismo contra el ateísmo». ${ }^{110}$

En los meses de diciembre de 1938 y enero de 1939, el Medical Bureau and North American Committee to Aid Spanish Democracy llevó a cabo una intensa campaña para que el Congreso de Estados Unidos levantara el embargo de envío de armas a España: entrevistas con congresistas, notas de prensa, impresión de 50.000 tarjetas navideñas con un texto impreso en el que se solicitaba al

\footnotetext{
${ }^{106}$ Cf. Carta de Isidro Gomá a Michael J. Ready, Toledo, 22-VIII-1938, en ACUA, National Catholic Welfare Conference, Box 51 Folder 2.

${ }^{107}$ Cf. Carta de Isidro Gomá a Michael J. Ready, Pamplona, 6-X-1938, en ACUA, National Catholic Welfare Conference, Box 51 Folder 3.

${ }^{108}$ Cf. Copia de carta de Franklin D. Roosevelt a John W. McCormack, 10-X-1938, en ACUA, National Catholic Welfare Conference, Box 51 Folder 3.

109 «world war and holy war of Christianity aginst atheism» (2-XII-1938. Philadelphia Record).

110 «Barcelona regime as Communistic and that they interpreted the situation in Spain as a war of Christianity against atheism» (Memorandum a mons. Ready, 31-XII-1938, en ACUA, National Catholic Welfare Conference, Box 51 Folder 3).
} 
Presidente de Estados Unidos que levantara el embargo como regalo de Navidad a la República española. ${ }^{111}$

Del 9 al 14 de enero, tuvo lugar la "Lift the Embargo Week" con el fin de recaudar dinero y atraer la atención de los medios de comunicación. La campaña argumentaba que el fascismo español era un peligro para las democracias en Latinoamérica y también en Europa. El triunfo de Franco sería también una victoria de Hitler y Mussolini. El pueblo español anhelaba la libertad frente al autoritarismo; y el embargo contradecía otros acuerdos firmados con España anteriormente. ${ }^{112}$

A diferencia de lo ocurrido en la campaña de la primavera de 1938, esta vez el mundo católico respondió de modo contundente. El 19 de diciembre, Ready convocó una reunión en la NCWC para ver qué pasos podían dar. ${ }^{113}$ Después de varias discusiones, se resolvió que el National Council of Catholic Men, el organismo para los laicos de la NCWC, crearía el Keep the Spanish Embargo Comittee. Louis Kennedy, presidente del National Council of Catholic Men, anunció la creación del comité el 30 de diciembre. Entre sus miembros se encontraba el arzobispo de Baltimore, Michael J. Curley; el secretario general de la NCWC, Michael J. Ready; el sacerdote Fulton Sheen y el jesuita Francis X. Talbot.

El Comité imprimió hojas volanderas, folletos y hojas con peticiones formales para el Congreso. Por su parte, la NCWC publicó un largo folleto a favor del embargo, redactado por Herbert Wright, profesor de Derecho Internacional en la Universidad Católica de América. ${ }^{114}$ Este material fue enviado a los directores de información de las diócesis norteamericanas, solicitando que se distribuyera entre los católicos. El 31 de diciembre, el Comité envió una tarjeta postal a todos los párrocos de Estados Unidos pidiendo la cooperación de sus parroquianos. Tres semanas más tarde, el Comité tuvo noticia de más de millón y medio de firmas de católicos de Estados Unidos en las que se pedía al Congreso el mantenimiento del embargo ${ }^{115}$.

La campaña ocupó buena parte del trabajo de Ready y de sus colaboradores en la NCWC. El 9 de enero, y en coincidencia con el inicio de la "Lift the Embargo Week", los católicos organizaron un acto multitudinario en el Constitution Hall de Washington. El aforo de unas 4.000 personas se llenó y varios centenares no pudieron entrar. Las intervenciones en el encuentro fueron publicadas y entregadas a todos los miembros del Congreso. Algunos congresistas, como Joachim O. Fernández, católico y demócrata, no dudaron en afirmar «my own sympathy with Nationalist Spain». ${ }^{116}$

${ }^{111}$ Un tarjetón con estas características puede verse en ACUA, National Catholic Welfare Conference, Box 51 Folder 3.

${ }^{112}$ Cf. Panfleto "Why the Embargo Against the Spanish Republic Should Be Lifted NOW", del Medical Bureau and North American Committee to Aid Spanish Democracy, en ACUA, National Catholic Welfare Conference, Box 51 Folder 4.

${ }^{113}$ La información que sigue se encuentra en "Memorandum, the Keep the Spanish Embargo Committee", Washington, 19-I-1939, en ACUA, National Catholic Welfare Conference, Box 51 Folder 4.

${ }^{114}$ Cf. "Memorandum in Support of the Retention of the Spanish Embargo", Washington, I-1939, en ACUA, National Catholic Welfare Conference, Box 51 Folder 4.

115 Cf. Carta de Louis Kenedy a Michael J. Ready, 14-I-1939, en ACUA, National Catholic Welfare Conference, Box 51 Folder 4, y Memorandum de Edward J. Heffron, secretario de Keep the Spanish Embargo Committee a los miembros del Comité, 27-I-1939, en ACUA, National Catholic Welfare Conference, Box 51 Folder 4.

${ }^{116}$ Carta de Joachim O. Fernández a J.F. Rummel, arzobispo de Nueva Orleans, Washington, 11-I-1939, en ACUA, National Catholic Welfare Conference, Box 51 Folder 4.

Hispania Sacra, LXIV Extra I, enero-junio 2012, 315-341, e-ISSN: 1988-4265, doi: 10.3989/hs.2012.033 
A finales de enero, el Congreso renunció a adoptar cualquier resolución sobre el embargo. El Comité católico pro-embargo había ganado la partida. Había conseguido llevar a cabo una movilización sin precedentes entre los católicos norteamericanos: más de dos millones de firmas en pocas semanas. ${ }^{117}$ Según Floyd L. Begin, sacerdote de la curia de la diócesis de Cleveland, «éste es el primer movimiento del que he sido testigo en Estados Unidos en el cual todos los católicos han tenido el mismo objetivo. Prominentes portavoces que se encuentran generalmente en lugares opuestos se han juntado en este movimiento». ${ }^{118}$

La campaña evidenció el poder político de los católicos en su particular defensa anti-comunista del país. Según decía Ready al Obispo de Cleveland, la «campaña tuvo un éxito enorme y, más allá del objetivo inmediato, fue de especial importancia que se consiguiera reducir a todos los cruzados de la "democracia roja"»." ${ }^{119}$

A modo de curiosa contrarréplica, Fernando de los Ríos, embajador de España, invitó públicamente a varios católicos para que acudieran a España. Entre otros, escribió a mons. Ready y al arzobispo de Baltimore, Michael J. Curley. ${ }^{120}$ Ready contestó al embajador y a la prensa que ya había solicitado en la primavera de 1938 el visado para ir a la España republicana y le fue negado. ${ }^{121} \mathrm{El}$ embajador insistió en una nueva carta del 17 de enero, aduciendo que en su día no recibió ninguna comunicación de mons. Ready. Añadió, en tono polémico, que podría encontrar en la zona republicana «a los miles de masones, profesores y diputados de izquierdas [que] todavía siguen vivos porque tuvieron la oportunidad de escapar de la zona rebelde». ${ }^{122}$

El 2 de febrero, Ready respondió a Fernando de los Ríos. En esas dos semanas, las circunstancias habían cambiado, pues el 27 de enero llegó la noticia de la caída de Barcelona, haciendo ya imposible una visita a la España republicana. La guerra estaba a punto de acabar, y de los Ríos iba a convertirse en un refugiado político. Antes de que dejara la embajada, mons. Ready quería aclarar con él algunos puntos. Además de ser la última, esta carta del Secretario general de la NCWC es la más dura de cuántas se cruzó con el socialista español. Ready la comenzó con el recuerdo de los asesinatos de clérigos inocentes: «desafortunadamente, nunca hubo una declaración oficial del Gobierno [de la

${ }^{117}$ Cf. Carta de Edward J. Heffron, secretario del National Council of Catholic Men, a Michael J. Ready, Washington, 8-III-1939, en ACUA, National Catholic Welfare Conference, Box 51 Folder 5.

118 «this is the first movement which I have witnessed in the United States in which all Catholics are of one mind. Prominent speakers who are usually on opposite sides have all joined you in this movement» (carta de Lloyd L. Begin a Michael J. Ready, 17-I-1939, en ACUA, National Catholic Welfare Conference, Box 51 Folder 4).

119 «campaign had a tremendous success and beyond the immediate objective the by-product of deflating the whole ilk of crusaders for red democracy was of special importance» (Carta de Michael J. Ready a Joseph Schrembs, Obispo de Cleveland, Ohio, Washington, 20-II-1939, en ACUA, National Catholic Welfare Conference, Box 51 Folder 5).

${ }^{120}$ Cf. Copia de la carta de Fernando de los Ríos a Louis Kenedy, Presidente de Keep the Embargo Committee, Washington, 9-I-1939, en ACUA, National Catholic Welfare Conference, Box 51 Folder 4.

${ }^{121}$ Cf. Carta de Michael J. Ready a Fernando de los Ríos, 14-I-1939, en ACUA, National Catholic Welfare Conference, Box 51 Folder 5; Catholic Cronicle, Toledo, Ohio, 13-I-1939.

122 «thousands of masons, professors and leftist deputies still alive because they were able to escape from rebel territory» (Carta de Fernando de los Ríos a Michael J. Ready, 17-I-1939, en ACUA, National Catholic Welfare Conference, Box 51 Folder 5). 
República española] de condena ni el Gobierno adoptó las medidas necesarias para frenar los continuos excesos contra la religión». ${ }^{123}$

Después, Ready añadió que los problemas venían de atrás, desde el momento en el que se aprobó la Constitución de 1931 que «negaba a la religión la apreciada libertad de una verdadera democracia». Frente a la primera enmienda de la Constitución americana, que declaraba que "el Congreso no hará una ley sobre el establecimiento de una religión ni prohibirá el libre ejercicio de la misma", el artículo 26 de la Constitución española indicaba que "Todas las confesiones religiosas serán consideradas como Asociaciones sometidas a una ley especial". Este artículo, seguía Ready, era «directamente opuesto al principio democrático de libertad enunciado en la Constitución de los Estados Unidos. Usted, Sr. Embajador, defendió una doctrina totalitaria dando a la República la autoridad para legislar en todos los asuntos concernientes con la religión. Bajo este mandato constitucional, la libertad religiosa se sujeta al Estado y no es reconocida como un derecho natural inalienable del ciudadano». ${ }^{124}$ Lo mismo ocurría con la prohibición de enseñanza a los religiosos o la inscripción de los mismos en un registro especial dependiente del Ministerio de Justicia: «los epígrafes sobre la educación y los mandatos que regulan las órdenes religiosas son ulteriores evidencias del carácter no democrático de la Constitución de $1931 » .{ }^{125}$ Se despedía Ready pensando en el futuro de España, futuro en el que los dirigentes de la República no estarían presentes: «todos los que aman España rezan por ella, y se alegran por establecimiento de la paz y la justicia en un pueblo que ha dado al mundo una herencia incalculable de cultura cristiana». ${ }^{126}$

El 1 de abril de 1939, Franco anunció el final de la guerra civil. Ready felicitó por la victoria a Juan F. de Cárdenas, representante del Gobierno Nacional, que se lo agradeció. Se había abierto un periodo nuevo, una dictadura, que exigía una justificación ante la opinión pública norteamericana. Según Cárdenas, «mi deseo es que el pueblo americano entienda ahora los altos ideales por los que hemos estado luchando». ${ }^{127}$

Pero Mons. Ready y su equipo de la NCWC se mantuvieron donde estaban. Deseaban que España se asentase en el concierto internacional, dando pasos hacia una futura democracia y evitando los compromisos con las ideologías fascistas. Según Ready, «si España logra apartarse del Eje y mantiene una fuerte posición de independencia, su causa en los Estados Unidos será bien atendida.

123 «Unfortunately, no official Government condemnation of these acts was ever announced nor were adequate measures taken by the Government to curb the continuing excesses against religion» (Carta de Michael J. Ready a Fernando de los Ríos, Washington, 2-II-1939, en ACUA, National Catholic Welfare Conference, Box 51 Folder 5).

124 «That is the direct opposite of the democratic principle of freedom enunciated in the Constitution of the United States. You, Mr. Ambassador, defended the totalitarian doctrine empowering the Republic to legislate in all matters concerning religion. Under such a constitutional provision, religious liberty becomes a thing subject to the State and is not recognized as a natural inalienable right of the citizen» (ídem).

125 «The educational clauses and the provisions regulating religious orders are additional evidence of the non-democratic character of the 1931 Constitution» (idem).

${ }^{126}$ «all who love Spain pray for and will rejoice in the establishment of peace and justice for a people who have given to the world a priceless heritage of Christian culture» (idem).

127 «my desire is that the American people realizes now the high ideas for which we have been fighting» (carta de Juan F. de Cárdenas a Michael J. Ready, 5-IV-1939, en ACUA, National Catholic Welfare Conference, Box 51 Folder 5). 
Muchos de nosotros, que defendimos la causa nacional durante la guerra civil, no vemos con complacencia algunas de las manifestaciones de amistad con Alemania». ${ }^{128}$

\section{CONCLUSIÓN}

La guerra civil española fue seguida con interés en los Estados Unidos. Ese conflicto era en cierto sentido el ápice de los problemas internacionales de finales de los años treinta: la internacionalización del comunismo, el crecimiento del fascismo y del nazismo en Europa, y la crisis de las democracias liberales en Occidente.

Muchas de las informaciones sobre la guerra española fueron simplistas o partidistas. No se utilizaron argumentos racionales a la hora de analizar las causas de su inicio y desarrollo. La propaganda, especialmente la favorable a los a republicanos, fue constante. La opinión pública norteamericana que se interesó por la guerra se decantó por uno de los dos bandos. Para el mundo liberal y protestante, era un conflicto entre un sistema democrático atacado y un fascismo agresor; para los católicos, era una defensa del catolicismo perseguido frente al totalitarismo comunista.

La National Catholic Welfare Conference tuvo información contrastada sobre la guerra civil. Durante los primeros meses, William F. Montavon, director del departamento jurídico, fue el portavoz ante los medios de comunicación. Insistió, sobre todo, en la brutal persecución religiosa en la zona republicana. En cambio, a partir de la publicación de la Carta Colectiva de los Obispos españoles a los de todo el mundo con motivo de la Guerra en España (1 de septiembre de 1937), Mons. Michael J. Ready, secretario general de la NCWC, lideró la respuesta católica sobre la guerra. Ready salió a la palestra porque temía el auge del comunismo en su país y porque la Iglesia católica norteamericana había sido atacada en la prensa por diversas denominaciones protestantes.

Después de la incertidumbre de los primeros meses, la NCWC, y con ella la mayoría de los católicos norteamericanos, se decantaron a favor de Franco. Los principales motivos fueron dos: la persecución religiosa, que no fue condenada por el Gobierno republicano, y la carta colectiva de los obispos españoles de septiembre de 1937, favorable a los nacionales. Los obispos americanos pensaron que la victoria de Franco ayudaría a todos los países -en su caso, a Estados Unidos- a prevenir el crecimiento del comunismo internacional.

Dentro del país hubo apoyos a ambos bandos, de acuerdo con la Iglesia o la posición política que tuviese cada uno. Los católicos ayudaron a los nacionales mediante la propaganda y el dinero, y los protestantes hicieron lo mismo con los republicanos. La NCWC insistió en la tradicional doctrina norteamericana de no intervención en los conflictos internos de otros países, se opuso a que fuesen voluntarios norteamericanos a luchar en las Brigadas Internacionales, y denunció ante el Gobierno federal los casos de reclutamiento ilegal. El presidente Roosevelt y el Congreso no tomaron partido por una zona u otra. Mantuvieron el embargo de armas a pesar de que muchos -entre otros, el Presidentedeseaban la victoria republicana.

128 «If Spain succeeds in Keeling out of the Axis and if she maintains a strong position of complete independence, her cause in the United States will be better served. Many of us who defended the Nationalist cause in the civil war do not view complacently some of the shows of friendship with Germany» (Carta de Michael J. Ready a Michael Williams, Washington, 5-VI-1939, en ACUA, Collection 10, Box 135, Folder 5). 
El apoyo al general Franco exigió a la NCWC responder a dos preguntas. La primera hacía referencia al carácter del Alzamiento nacional, visto por muchos como una rebelión armada contra un régimen democrático legítimamente constituido. La segunda se refería al régimen del general Franco, una Junta de Defensa Nacional que dio paso a un Gobierno autoritario con aires fascistas.

La NCWC desacreditó en repetidas ocasiones a la Constitución de 1931 y al Gobierno republicano del Frente Popular, elegido de modo dudoso en febrero de 1936. Ese Gobierno había sumido al país en el caos social en pocas semanas y no había condenado el asesinato de católicos inocentes al comienzo de la guerra. Deslegitimado el Gobierno, resultaba más sencillo explicar por qué la rebelión de Franco era justa. Pero, a partir de 1937, la situación se complicó. El Gobierno republicano dio tímidos pasos hacia un sistema más ordenado movido, en parte, por la presión internacional y por la mala imagen dada por los asesinatos. Para seguir deslegitimando al Gobierno, la NCWC mantuvo durante toda la guerra la misma máxima: el Gobierno republicano estaba controlado por los comunistas.

Para la NCWC, la guerra había sacado a la luz el verdadero enemigo político, social y religioso: el comunismo. Este sistema ateo se había propuesto desde el principio de la guerra destruir la religión en España. Los comunistas habían utilizado las mismas tácticas que emplearon en Rusia y México: violencia intelectual y violencia física. En el año 1936, los asesinatos de los líderes de la Iglesia en España, obispos y sacerdotes habían sido sistemáticos y brutales. Los revolucionarios tomaron el mando efectivo de la guerra en la zona republicana y aplicaron a rajatabla la consigna de eliminación física de la Iglesia. No se trataba de una guerra de religión ni de una guerra de carácter social entre ricos y pobres. Era una guerra de defensa de católicos que creían en la libertad de religión.

La fuerte crítica de los obispos norteamericanos al comunismo en España les ayudó a envolver el problema de la ayuda que recibía Franco por parte del fascismo y del nazismo. ${ }^{129}$ La crítica situó políticamente a los católicos frente a los sucesos que iban a producirse en los años cuarenta y cincuenta en Estados Unidos. La jerarquía y los fieles católicos aparecieron ante la opinión pública como ciudadanos esencialmente anticomunistas. Estos sucesos dieron a los católicos americanos una reputación de fuerte poder político, más del que poseían en realidad. ${ }^{130}$

La NCWC tuvo claro que el régimen de Franco no era fascista ni mucho menos nazista. Negó repetidas veces que fuese una guerra de Italia, Alemania, Portugal y los musulmanes del norte de África contra los españoles. Temía que se identificara el fascismo con el catolicismo español, pues podía tener efectos adversos en la imagen del catolicismo en Estados Unidos. ${ }^{131}$ Pensaba, además, que España no tenía tradición totalitaria y que, por tanto, ni el fascismo ni el comunismo podían triunfar a largo plazo en suelo peninsular. ${ }^{132}$ Deseaba un sistema democrático para España.

Pero el apoyo a Franco debilitó a los católicos norteamericanos. Se quedaron prácticamente solos en la defensa de la zona nacional. Se les tildó de pro-fascistas. Formaron un ghetto frente a la

${ }^{129}$ Cf. Frank, R. L. 1992. "Prelude to Cold War: American Catholics and Communism". Journal of Church and State 58: 39-56.

${ }^{130}$ Cf. Flynn G. Q. 1976: 52.

${ }^{131}$ Cf. Taylor F. J. 1956. The United States and the Spanish Civil War: 153. New York: Bookman Associates.

${ }^{132}$ Cf. Benn, W. J. 1937. "Further Processes in Spanish Sovietization. Training the Youth in Materialism and Class Hatred". America 57: 585.

Hispania Sacra, LXIV Extra I, enero-junio 2012, 315-341, e-ISSN: 1988-4265, doi: 10.3989/hs.2012.033 
mayoría de los norteamericanos, partidarios de la República, y quedaron imposibilitados para el diálogo ecuménico con las denominaciones protestantes. ${ }^{133}$

En los años treinta, los dirigentes de la NCWC trataban de explicar que se podía ser, a la vez, católico y norteamericano, leal a la Iglesia y leal al país. Eran demócratas convencidos. Veían la separación de la Iglesia y el Estado en Estados Unidos como un valor permanente. Creían en la libertad del hombre para ejercer su religión. Según Ready, «nuestra defensa consiste en enfatizar que creemos en la democracia y que apoyamos al poder constituido de cualquier tipo de gobierno que reconozca los derechos inalienables e innatos basados en la dignidad del hombre y que respete la libertad de conciencia ${ }^{134}$. Los comunistas, los sin-Dios, habían destruido España. Ese era el mal que América nunca debía padecer. En una conferencia dada a la Federación Internacional de Alumnos Católicos, reunidos en Cleveland en el verano de 1938, Ready declaró: «una intensa fe religiosa caracterizó a los grandes fundadores de esta Democracia, y la defensa y gloria de sus instituciones permanecen en aquellos que ven en el hombre algo más que un ciudadano de la Tierra. Conservad a América grande dándole el espíritu de piedad, caridad y justicia que la Iglesia, vuestra común Alma Mater, os ha dado» ${ }^{135}$.

\section{BIBLIOGRAFÍA}

1936. Boletín Oficial Eclesiástico del Obispado de Pamplona 1832: 317-322.

1937. Carta Colectiva de los Obispos españoles a los de todo el mundo con motivo de la Guerra en España. Pamplona: Gráficas Bescansa.

1938. "El Sr. Obispo de Toledo (Ohio) ha visitado Toledo". Boletín Eclesiástico del Arzobispado de Toledo 10: 315-318.

Andrés-Gallego, J. y Pazos, A. M. 2001-2010. Archivo Gomá: Documentos de la Guerra Civil. Madrid: Consejo Superior de Investigaciones Científicas.

Arrambide, P. M. 1976. The reaction of the Protestant and Catholic churches in the U.S.A. to the Spanish Civil War. Tesis doctoral. Memphis State University.

Bosch, A. 2012. Miedo a la democracia: Estados Unidos ante la Segunda República y la Guerra Civil española. Barcelona: Crítica.

Carey P. W. 2004. Catholics in America. A History. Westport (CT): Praeger

${ }^{133}$ Cf. Tusell, J. y García Queipo de Llano, G. 1993: 364.

134 «Our defense is to emphasize that we believe in democracy and support constituted authority under any type of government which acknowledges the antecedent and inalienable rights based on the dignity of man and which respects liberty of conscience» (Carta de Michael J. Ready a Thomas A. Welch, 18-I-1937, en ACUA, National Catholic Welfare Conference, Box 50 Folder 22).

135 «A strong religious faith characterized the great founders of this Democracy and the defense and glory of its institutions rest in those who see in man more than a citizen of Earth. Keep America great by giving it the spirit of piety, charity and justice which the Church, your common Alma Mater, has given you» (Michael J. Ready, Nota de prensa de N.C.W.C. News Service, 29-VIII-1938, en ACUA, National Catholic Welfare Conference, Box 51 Folder 2). 
Cortada, J. W. 1982. Historical dictionary of the Spanish Civil War, 1936-1939: 105-106. Westport: Greenwood Press.

Dionisio Vivas, M. A. 2011. Isidro Gomá ante la dictadura y la República: pensamiento políticoreligioso y acción pastoral. Toledo: Instituto Teológico San Ildefonso.

Dolan, J. P. 1985. The American Catholic Experience: a History from Colonial Times to the Present. Garden City (NY): Doubleday \& Co.

Flynn G. Q. 1976. Roosevelt and Romanism. Catholics and American Diplomacy, 1937-1945. Westport (Conn.): Greenwood Press.

Frank, R. L. 1978. The rhetoric of American Catholicism on the Spanish Civil War. Tesis doctoral. University of Pittsburgh.

Frank, R. L. 1992. "Prelude to Cold War: American Catholics and Communism". Journal of Church and State 58: 39-56.

Gomá y Tomás, I. 1940. "Discurso en la recepción dada en Toledo a Mons. Alter", en Por Dios y por España. Barcelona: Casulleras.

Hernández Figueiredo, J. R. 2010. “Avances y estado del comunismo en vísperas de la guerra civil española, según los informes inéditos del Archivo Secreto Vaticano". Analecta Sacra Tarraconensia 83: 817-906.

Maynard, T. 1948. The Story of American Catholicism. New York: The Macmillan Company.

Montavon W. F., 1936. Insurrection in Spain. Washington (D.C.): National Catholic Welfare Conference.

Prudlo D. 2006. "American Catholics and the Spanish Civil War". Faith and Reason 31,2: 243-273.

Redondo, G. 1993. Historia de la Iglesia en España. 1931-1939, tomo II, "La Guerra Civil (19361939)". Madrid: Rialp.

Rey García, M. 1996. "Fernando de los Ríos y Juan F. de Cárdenas: dos embajadores para la guerra de España (1936-1939)”. Reden 11: 129-149.

Ruiz-Manjón, O. 2007. Fernando de los Ríos: un intelectual en el PSOE. Madrid: Editorial Sintesis.

Sánchez, J. M. 1987. The Spanish civil war as a religious tragedy. Notre Dame (Indiana): University of Notre Dame Press.

Sánchez J. M. 1992. "Priests and Suspect Catholics: Visitors from Loyalist Spain to America". The Catholic Historical Review LXXVIII/2: 207-216.

Taylor F. J. 1956. The United States and the Spanish Civil War: 153. New York: Bookman Associates.

Traina R. P. 1968. American Diplomacy and the Spanish Civil War. Bloomington-Londres: Indiana University Press.

Tusell, J. y García Queipo de Llano, G. 1993. El catolicismo mundial y la guerra de España: 297-364. Madrid: BAC.

Van Allen, R. 1974. The Commonweal and American Catholicism: the magazine, the movement, the meaning. Philadelphia: Fortress Press. 